\title{
RESERVA LEGAL E INCONSISTENCIAS DEL RECURSO DE PROTECCIÓN: UN CASO SOBRE LOS INSTRUCTIVOS DEL MinisTerio PÚBLICO*
}

\author{
KATHERINE BECERRA VALdivia**
}

En Chile, a la luz de lo señalado por nuestra Constitución las potestades normativas de los órganos del Estado no están totalmente estructuradas y delimitadas según lo indicado en el artículo 63, que establece las materias de ley, y el artículo $32 \mathrm{~N}^{\circ} 6$, que otorga la atribución administrativa al Presidente de la República de dictar normas de carácter infralegal, denominada potestad reglamentaria.

A estas dos atribuciones de competencia, establecidas a dos de los poderes del Estado, hay que incorporarles en la actualidad otras atribuciones normativas, la mayoría de ellas de carácter legal, a una serie de organismos constitucionales autónomos, tales como el Banco Central, tribunales electorales, Tribunal Constitucional y, por cierto, el Ministerio Público. Es dentro de este contexto que cabe el análisis de la sentencia Rol 77 - 2010 de la Corte de Apelaciones de La Serena, en donde se recurre de protección frente a la negativa del Fiscal Regional de acceder a una suspensión condicional del procedimiento en un delito por conducción en estado de ebriedad simple, basado en un instructivo emitido por él mismo, en virtud del cual establece la procedencia de aquella salida alternativa, considerándose, por el recurrente, que esta negativa es discriminatoria y que, por tanto, vulnera el derecho de igualdad ante la ley, establecido en el artículo 19 N 2 de la Constitución Política de la República, pues se produce una discriminación arbitraria. Cabe destacar que el tribunal, rechazó la acción de protección incoada.

Al analizar esta sentencia se puede establecer, a primera vista, que existen varias aspectos dignos de análisis: el contenido esencial de la igualdad ante la ley, si en el caso de autos hay discriminación arbitraria, establecer si hay otros conflictos constitucionales relevantes, determinar si mediante los instructivos del Ministerio Público, y en especial del Fiscal Regional, como es en este caso, se ha conculcado la garantía normativa de

Este comentario es una versión mejorada del trabajo final realizado por la autora en el Módulo "Garantías normativas y jurisdiccionales de los derechos fundamentales" del Programa de Magíster en Derecho impartido por la Escuela de Derecho de la Universidad Católica del Norte, sede Coquimbo, el que fue aprobado con calificación sobresaliente.

** Abogada, Profesora Auxiliar de Derecho Constitucional en la Universidad Católica del Norte, sede Coquimbo. Correo electrónico: kbecval@gmail.com 
reserva legal; y también analizar si la consideración de la Corte, en cuanto a que esta acción no era susceptible de amparo, toda vez que el acto era legal, se condice con la finalidad de la acción de protección como un mecanismo de tutela de derechos fundamentales, más allá de lo meramente legal. Para no extender este comentario, nos quedaremos en estos dos últimos puntos.

En cuanto al primer análisis propuesto hay que señalar que la atribución del Fiscal Nacional y de los fiscales regionales para dictar instrucciones provienen de la Ley Orgánica Constitucional del Ministerio Público $N^{\circ}$ 19.640, en los artículos 17 letra a) y 32 letra a), respectivamente. Cuando inició sus actividades el Ministerio Público, luego de la entrada en vigencia de la nueva institucionalidad procesal penal, se discutió en reiteradas ocasiones el origen constitucional o no de esta atribución, toda vez que la Constitución nada dice a este respecto. Hay autores como Aldunate, que deslizan de manera implícita, que desde su orígenes estas serían inconstitucionales, toda vez que para determinar si tienen o no una habilitación de tipo constitucional habría que subsumirlas en tres realidades distintas: son parte de la Superintendencia directiva, correccional y económica que le entrega la Constitución al Fiscal Nacional, pero la verdad es que en el mismo artículo 17 letra d) se establece otro producto normativo como consecuencia de esta Superintendencia: los reglamentos; otra solución plantea que es parte de la jerarquía superior que le entrega al Fiscal Nacional nuestra Constitución o, en último lugar, es una opción legislativa entregarle esta facultad con el objeto de hacer patente su independencia, autonomía y responsabilidad en el ejercicio de la investigación y de la acción penal pública ${ }^{1}$. Si bien es cierto que estas consideraciones son para el Fiscal Nacional, deberíamos desprender que la facultad de dictar instructivos del Fiscal Regional, que afectan no solo al servicio, sino que a terceros usuarios del sistema de justicia, la podríamos inferir de la representación que tiene este último del Fiscal Nacional en la respectiva región, y que está establecida en el artículo 27 de la norma ya mencionada.

Pero más allá de estas consideraciones hay que determinar si la dictación de estos productos normativos se ajustan al ámbito competencial entregado, en el entendido que este instructivo regula una salida alternativa del procedimiento como lo es la Suspensión Condicional del Procedimiento, establecida en el artículo 237 del Código Procesal Penal, estableciéndose como una facultad para el Fiscal, quien con acuer-

Aldunate, Eduardo (2009). "La distribución de potestades normativas en la Constitución: potestades reglamentarias administrativas, autos acordados y facultades del fiscal nacional", Revista de Derecho de la Pontificia Universidad Católica de Valparaiso, XXXIII, Valparaíso, Chile, 2o Semestre, pp. 371-390. Disponible en: http://www.scielo.cl/scielo. php?pid=S0718-685120090002000108script=sci_arttext, p. 388 [Fecha de visita: 3 de julio de 2010]. 
do del imputado, puede solicitarla cumpliéndose con los presupuestos entregados por el mismo artículo. La pregunta que cabe hacerse en este entendido es si puede un instructivo desarrollar esta facultad, e incluso poner más requisitos que los establecidos por la ley, a veces incurriendo en discriminaciones, teniendo en consideración, además, que estamos hablando de un ámbito de leyes procesales penales en donde existe una reserva de ley, según lo establece la Constitución en su artículo $63 \mathrm{~N}^{\circ} 2$ y 3 .

Independiente de si creamos o no que esta facultad forma parte del debido proceso o de la tutela judicial efectiva, es decir, un derecho fundamental, evidentemente hay una infracción a la reserva de ley, toda vez que las materias indicadas son parte de la codificación penal y procesal en general, y solo pueden ser reguladas por ley, lo que hace la diferencia es el tipo de reserva legal, pues en el primer caso planteado la reserva sería general y absoluta, pues hay un mandato amplio al legislador y la intromisión del Ejecutivo se debe limitar solo a las normas de detalle y ejecución, pues es el legislador quien tiene que asumir una mayor densidad normativa. En cambio en el segundo caso planteado la reserva sería específica y relativa, pues hay un mandato particular al legislador, y a la ley solo le corresponde establecer las grandes directrices del tema a tra$\operatorname{tar}^{2}$.

En mi opinión, creo que estamos frente a un caso de derechos fundamentales, toda vez que la Constitución en el artículo $19 \mathrm{~N}^{\circ} 3$ establece claramente que tanto la investigación y el procedimiento deben ser determinados con garantías de racionalidad y justicia, es decir, el establecimiento de una institución procesal debe contar con estas dos características, y por tanto la facultad de utilizar o no esta salida alternativa, tiene que ser asimismo racional y justa, puesto que la ley debería dar los parámetros para lograr este estándar de garantía, y si no los entrega la ley, la potestad normativa no puede suplir esta falencia del legislador ni muchos menos incurrir en discriminaciones en torno a la procedencia o no de aquella para el caso específico, como sucede en esta causa.

Para llevar a cabo este análisis, hay que tener además en especial consideración el control de constitucionalidad en abstracto llevado a cabo por el Tribunal Constitucional en su sentencia Rol $N^{\circ} 293$, que declaró inconstitucional la palabra "reglamento" del artículo $6^{\circ}$ de la referida Ley Orgánica Constitucional que en su texto original indicaba: "Los procedimientos del Ministerio Público deberán ser ágiles y expeditos, sin más formalidades que las que establezcan las leyes y reglamentos, y pro-

2 Cazor Aliste, Kamel (2002). La Sumisión a Derecho de los Actos y Disposiciones del Presidente de la República. Santiago: Universidad Central de Chile, Facultad de Ciencias Jurídicas y Sociales, Tomo I, pp. 110-133. 
curarán la simplificación y rapidez de sus actuaciones". Lo que llama la atención es que la argumentación entregada para declarar esta inconstitucionalidad se basa en que el constituyente le entrega al legislador la atribución de establecer las garantías de un procedimiento e investigación racional y justo, por ende, al Ministerio Público no le corresponde, mediante normas infralegales, establecer conducta ninguna respecto a la investigación ni menos del procedimiento, pero la pregunta que cabe hacerse es si no está haciendo esto mismo cuando mediante "instructivos" establece e impone límites o condiciones al ejercicio de una institución de orden procesal penal como la suspensión condicional del procedimiento, institución que por lo demás tiene el efecto de terminar con este último.

Este análisis no se plantea en la sentencia que está siendo comentada, pues en ningún considerando se esboza, al menos, el contenido del instructivo, o peor aún, basándose la sentencia en este documento, este ni siquiera está acompańado en la causa, solo se habla y se acompaña el oficio con la negativa de acceder a la suspensión del procedimiento. En todo caso, habría que decir desde ya que es posible encontrar algunas opiniones, en el sentido de que lo aquí planteado escapa a las facultades que involucran la resolución de la acción de protección, toda vez que la Corte de Apelaciones no sería el organismo legitimado constitucionalmente para resolver este asunto de constitucionalidad, pero la verdad es que creo que en este caso, y en atención a las medidas que puede tomar el órgano para restablecer el imperio del Derecho, sí podría dejar sin efecto aquel instructivo, por exceder, en primer lugar, el ámbito de competencia, y porque efectivamente estaría poniendo condiciones innecesarias y gravosas, o en último caso, no establecidas por la ley, para poder acceder a un beneficio, estableciendo aquello solo para algunos casos y para otros no, toda vez que el Fiscal Regional de Coquimbo podría poner condiciones distintas, bajo las mismas o similares circunstancias al Fiscal Regional de Antofagasta, o peor aún, actuar tomando distintas decisiones en casos iguales, como ocurre en esta situación y lo pone de manifiesto el recurrente con su acción de protección. Es importante indicar, además, que este tipo de instructivos no tiene ningún procedimiento de control ni de legalidad, ni mucho menos de constitucionalidad, por cuanto un pronunciamiento de la Corte de Apelaciones sobre este respecto, no estaría vulnerando ningún ámbito competencial de otro órgano.

Otro punto a destacar, es si una instrucción puede ser invocada como una norma jurídica vigente dentro de un procedimiento como el que se analiza, y más aún ser tomado en consideración por la Corte como una norma fundante de su fallo. Aquí encontramos opiniones diversas en cuanto a los efectos de estos productos normativos por parte de los autores, pues para Cordero Vega, la característica esencial de estos instructivos es que se dirigen a los funcionarios del Ministerio Público, y que en nin- 
gún caso podrían ser oponibles en un procedimiento a terceros ${ }^{3}$. Distinta es la opinión del profesor Aldunate, que seńala que estamos frente a una "potestad reglamentaria externa" en cuanto su cumplimiento afectará a terceros ajenos a la administración: imputados, víctimas y testigos, como destinatarios de las correspondientes acciones de investigación, acusación y protección" 4 . Podemos tomar aquí las palabras de los profesores Cea y Bulnes, quienes en un informe en Derecho señalan: "El objetivo de tales instructivos no es otro que el de explicar a los subordinados las normas de carácter constitucional o legal que estos deben considerar en el desarrollo de sus funciones e impartirles directivas para sus actuaciones en relación con las materias que estas ordenen, a fin de facilitar su aplicación en el cumplimiento de las tareas que a cada uno competan, procurando la coordinación y la unidad de acción y, además, evitando la duplicación o interferencia de funciones" 5 , por tanto, establecer como norma esencial del pronunciamiento del tribunal esta instrucción general, impartida mediante Oficio No 358 de 21 de febrero de 2008, estaría vulnerando completamente la función de este tipo de normas, pues es solo una instrucción dictada al interior del Ministerio Publico, que aun teniendo efectos en los operadores jurídicos, no resulta suficiente en la ratio decidendi del tribunal, más aún teniendo en vista las consideraciones de los párrafos anteriores. Es decir, se está usando una norma de carácter administrativa, que en la jerarquía se encuentra bajo la ley y la Constitución, para dar resolución a un conflicto en donde se ven limitados derechos fundamentales, utilizando una interpretación en contra y restrictiva de los mismos.

Siguiendo con el análisis, y entrando de lleno a la segunda propuesta, cabe establecer si esta resolución, de rechazar la acción, cumple con la finalidad de la acción de protección, la cual es tutelar un derecho fundamental conculcado, en este caso la igualdad, verificando si hay privación, perturbación o amenaza de una acción u omisión de naturaleza ilegal o arbitraria, teniendo a la vista, además, si el tribunal se queda solamente en estas últimas posibilidades.

Como ya se ha establecido, estamos frente a la negativa del Fiscal Regional de acceder a una suspensión condicional del procedimiento. En

3 Cordero Vega, Luis (2002). "El poder Normativo del Ministerio Público", Gaceta Jurídica No 259, enero, pp. 7-15. Disponible en: http://productos.legalpublishing.cl/ NXT/publishing.dll/A_Juridica/DOCTRINA/CL_MON05/a00000.htm/fallo00001. $\mathrm{htm}$ ?fn=document-frame.htm $\$ \mathrm{f}=$ templates $\$ 3.0$ Principio del formulario

Final del formulario

[Fecha de visita: 3 de julio de 2010], p.12.

4 Aldunate (2009) 385

5 Cea Egaña, José / Bulnes Aldunate, Luz (2001). Informe Sobre Instructivos del Fiscal Nacional del Ministerio Público en Oficio N 496 de 16 de noviembre, del Fiscal Nacional del Ministerio Público. Disponible en: www.fiscaliadechile.cl [Fecha de visita: 5 de julio de 2010]. 
el caso de autos el tribunal expresamente seńala en el considerando octavo que estamos frente a una facultad discrecional, toda vez que cumpliéndose con los requisitos establecidos en el artículo 237 del Código Procesal Penal, el Fiscal, con acuerdo del imputado, "podrá" pedirla o no al Juez de Garantía.

Lo que alega el recurrente es que con esta actuación ilegal y arbitraria se le privó de su derecho a ser beneficiado con una salida alternativa al procedimiento, y la verdad es que siendo discrecional esta facultad él no tenía derecho alguno a ser beneficiado, solo tenía una mera expectativa respecto a esta posibilidad, por lo tanto vemos aquí reflejado el fenómeno de la "vulgarización", mediante el cual la acción de protección se abre a proteger una serie de situaciones jurídicas no fundamentales e incluso intereses legítimos, como en este caso ${ }^{6}$.

En esta causa hay conculcación de derechos fundamentales, que efectivamente se relacionan con la igualdad, pero que tiene una identidad propia y que tienen que ver con el debido proceso y el derecho a tener una resolución razonablemente fundada, que es un derecho que no solo le asiste al juez, al dictar sentencia, sino que también los órganos del Estado deben dictar resoluciones motivadas, congruentes y razonables, con el objeto de proteger la dignidad de la persona y no permitir las arbitrariedades por parte de los poderes públicos, puesto que una resolución sin motivación es un acto de autoridad y no de justicia y además obstaculiza el derecho de defensa del ciudadano ${ }^{7}$. El tribunal intuye esto, pero se queda nuevamente en lo meramente legal, como se expondrá más adelante.

Y en este sentido, el Ministerio Público cuando entrega su negativa a esta salida alternativa da tres argumentos: el primero de ellos es en atención a la cantidad de alcohol en la sangre del imputado; el segundo, el carácter de delito abstracto de la conducción en estado de ebriedad, y finalmente señala que en Chile la segunda causa de accidentes de tránsito es el delito cometido. Argumentación que a todas luces sería insuficiente para justificar la negativa, pues son evidentemente generales y subjetivas, y van en contra del principio de objetividad que funda la actuación del Ministerio Público y no están viendo las circunstancias del caso concreto, por tanto no cumplen con el estándar adecuado de justificación racional que debiese existir en estos casos.

Estudiándolas una a una, podemos decir que frente a las dos primeras, su falta de adecuación se encuentra en el hecho que ambas argu-

6 Cazor Aliste, Kamel / Rojas Calderón, Christian (2009). "Las deficiencias estructurales y prácticas de la acción de Protección”. Revista de Derecho, Universidad Católica del Norte, Año $16 \mathrm{~N}^{\circ} 1$, pp. 169-190, pp. 184-182.

7 Hormazábal Malaré́, Hernán (2006). El Nuevo Tribunal Constitucional. Los Derechos Fundamentales y el Moderno Recurso de Inaplicabilidad, Santiago: Editorial LexisNexis, pp. 127-134. 
mentaciones son los hechos constitutivos del delito, es decir, habiendo aceptado o rechazado la solicitud, ambas eran hechos ocurridos y forman parte del ilícito penal, por tanto no es dable argumentar en base a aquellos porque no dicen nada al caso concreto. En cuanto a la última argumentación, y siguiendo al profesor Atienza, estamos frente a una respuesta de tipo estadística, que este autor califica como una argumentación no normativa, y por tanto, muy generales para dar una respuesta motivada tal como lo estamos viendo ${ }^{8}$.

A mayor abundamiento, y quedándonos en el tema de la arbitrariedad, nuestra Corte establece en el considerando octavo que "...el acto cuya ilegalidad y arbitrariedad se invoca, no constituye sino la respuesta a la solicitud que al efecto habia formulado la propia defensa del recurrente, respuesta que, por lo demás, ha sido debidamente motivada por el mencionado Fiscal Regional, según se infiere de la simple lectura del mencionado oficio, circunstancia que, entonces, impide al mero capricho del recurrido la decisión de negar la concesión de la pretendida salida alternativa", por lo tanto a la Corte de Apelaciones no le interesan los motivos y si son acorde a una respuesta bien fundada, solo le interesa que existan, es decir, el principio de racionalidad de los actos administrativos, en virtud del cual la Administración, y aquí incluyo al Ministerio Público, debe dar "razón suficiente" de su conducta, es decir, no basta con cualquier razón, esta tiene que ser una razón de esencia, de existencia y por cierto de verdad ${ }^{9}$, a la Corte pareciese no importarle y les da todo el peso legal, solo con el mérito de establecerlas en el oficio. Dichas razones, que ya fueron explicitadas, no cumplen con los estándares mínimos para no considerarlas arbitrarias, pues son acomodaticias y generales, y efectivamente conculcan la igualdad en el trato que hace el Fiscal Regional, pues de la lectura del expediente, queda de manifiesto que en condiciones más graves le ha dado lugar a esta salida alternativa.

Es del caso señalar que el recurrente relata que en una oportunidad anterior, teniendo más alcohol en la sangre que él, a un estudiante de Derecho se le concedió la salida alternativa, en atención a su condición de próximo a egresar de la carrera, siendo un alumno de excelencia (promedio superior a 6,0), por lo cual la consecución del juicio le podría causar algún problema para la obtención final del título y por tanto era justificado darle el beneficio. Pero el recurrente alega que en definitiva, a él como ingeniero agrónomo, funcionario de la I. Municipalidad de La

8 Atienza, Manuel (2006). El Derecho como Argumentación, Barcelona: Ariel Editores, p. 156.

9 Cassagne, Juan Carlos (2008). "La Prohibición de Arbitrariedad y el Control de la Discrecionalidad Administrativa por el Poder Judicial”. La Ley, año LXXII No 187 , Buenos Aires, Argentina, pp. 1-22. Disponible en: http://www.laley.com.ar/laley/cms/files/1280/ diario\%2029-9-08.pdf [Fecha de visita: 8 de julio de 2010], p. 7. 
Serena, esta situación también podría traerle consecuencias negativas en lo laboral, en atención a su situación de funcionario público. Es por esto, y sumado a la motivación dada por el Fiscal Regional, que creo que se actuó de una manera discriminatoria.

En atención a los argumentos recién expuestos es dable, entonces, señalar que aquí estamos frente al típico problema de la situación jurídica protegida: por un lado el tribunal le está dando amparo a una mera expectativa; y en segundo lugar, queriendo entrar de igual modo al análisis, pero desde otra perspectiva, lo desvincula totalmente de la Constitución, con el legítimo ejercicio de un derecho, quedándose en el primer paso del examen, es decir, solo en la arbitrariedad e ilegalidad, pero no lo está viendo con una perspectiva "desde la Constitución", por tanto vemos que pasando el examen de legalidad, como sería este caso, nada dirá el tribunal sobre una posible arbitrariedad ni muchos menos sobre la constitucionalidad o no de la actuación u omisión, pues sería innecesario al cumplirse el primer presupuesto ${ }^{10}$.

Esta visión de la acción de protección es tremendamente peligrosa, pues de una manera indirecta se está dejando sin efecto una obligación de tipo internacional asumida por Chile, toda vez que no se está cumpliendo con el artículo 25 de la Convención Americana de Derechos Humanos, que señala que "Toda persona tiene derecho a un recurso sencillo y rápido o a cualquier otro recurso efectivo ante los jueces o tribunales competentes, que la ampare contra actos que violen sus derechos fundamentales reconocidos por la Constitución, la ley o la presente Convención, aun cuando tal violación sea cometida por personas que actúen en ejercicio de sus funciones oficiales", en atención a que formalmente existe una acción protectora de derechos fundamentales, pero materialmente se queda como acción protectora de meros intereses o derechos subjetivos no fundamentales, donde lo esencial es la ley y no los derechos fundamentales emanados de la Constitución.

Como conclusión, se puede establecer que esta sentencia presenta una serie de inconsistencias, toda vez que nada dice sobre la intromisión de instructivos en ámbitos que no son de su competencia, quebrantando absolutamente el principio de reserva legal, más aún teniendo en consideración que el fallo constantemente discurre sobre la legalidad del acto basado en aquel instructivo, que ni siquiera tiene a la vista en la causa, teniendo también en consideración, que desde el estudio de la naturaleza jurídica de este producto normativo, la poca doctrina encontrada, no está de acuerdo en si tienen efecto para los terceros comparecientes en un juicio penal, toda vez que siendo mandatos al interior del Ministerio Pú-

10 Silva Irarrázabal, Luis Alejandro (2009). El Control de Constitucionalidad de los Actos Administrativos Legales. Un Análisis Jurisprudencial y Comparado, Santiago: LegalPublishing, p. 88. 
blico, no podrían ser utilizados en la sentencia por el tribunal; y además, desde otra perspectiva, se realiza el análisis del derecho conculcado, a través de una mera expectativa del recurrente, y queriendo entrar a la resolución del conflicto de igual modo, se queda en el análisis meramente legal, no dando lugar a una análisis de tipo constitucional.

\section{BibLIOGRAFÍA}

- Aldunate, Eduardo (2009). "La distribución de potestades normativas en la constitución: potestades reglamentarias administrativas, autos acordados y facultades del fiscal nacional", Revista de Derecho Pontificia Universidad Católica de Valparaíso, XXXIII, Valparaíso, Chile, 2o Semestre. Disponible en: http://www.scielo.cl/scielo. php?pid=S0718-68512009000200010\&script=sci_arttext [Fecha de visita: 3 de Julio de 2010].

- Atienza, Manuel (2006). El Derecho como Argumentación, Barcelona: Ariel Editores.

- Cassagne, Juan Carlos (2008). "La Prohibición de Arbitrariedad y el Control de la Discrecionalidad Administrativa por el Poder Judicial". La Ley, año LXXII N ${ }^{\circ} 187$, Buenos Aires, Argentina. Disponible en: http://www.laley.com.ar/laley/cms/files/1280/diario\%2029-9-08.pdf [Fecha de visita: 8 de julio de 2010].

- Cazor Aliste, Kamel (2002). La Sumisión a Derecho de los Actos y Disposiciones del Presidente de la República. Santiago: Universidad Central de Chile, Facultad de Ciencias Jurídicas y Sociales, Tomo I.

- Cazor Aliste, Kamel / Rojas Calderón, Christian (2009). "Las Deficiencias Estructurales y Prácticas de la Acción de Protección". Revista de Derecho, Universidad Católica del Norte, Año $16 \mathrm{~N}^{\circ}$ 1, pp. 169-192.

- Cea Egaña, José / Bulnes Aldunate, Luz (2001). Informe Sobre Instructivos del Fiscal Nacional del Ministerio Público en Oficio $\mathrm{N}^{\circ} 496 \mathrm{de}$ 16 de noviembre, del Fiscal Nacional del Ministerio Público. Disponible en: www.fiscaliadechile.cl [Fecha de visita: 5 de julio de 2010].

- Cordero Vega, Luis (2002). "El poder Normativo del Ministerio Público", Gaceta Jurídica No 259, enero, pp. 7- 15. Disponible n: http:// productos.legalpublishing.cl/NXT/publishing.dll/A_Juridica/DOCTRINA/CL_MON05/a00000.htm/fallo00001.htm?fn=documentframe.htm $\$$ f=templates $\$ 3.0$ [Fecha de visita: 3 de julio de 2010].

- Hormazábal Malaré́, Hernán (2006). El Nuevo Tribunal Constitucional. Los Derechos Fundamentales y el Moderno Recurso de Inaplicabilidad, Santiago: Editorial LexisNexis.

- Silva Irarrázabal, Luis Alejandro (2009). El Control de Constitucionalidad de los Actos Administrativos Legales. Un Análisis Jurisprudencial y Comparado, Santiago: LegalPublishing. 